ORIGINAL RESEARCH

\title{
Importance of Nutrition Visits After Gastric Bypass Surgery for American Veterans, San Francisco, 2004-2010
}

\author{
Aung Zaw Win, MD, MA, MPH; Carol Ceresa, MHSL, RD; Anne L. Schafer, MD; \\ Peter Mak, BS, RD; Lygia Stewart, MD
}

\begin{abstract}
Suggested citation for this article: Win AZ, Ceresa C, Schafer AL, Mak P, Stewart L. Importance of Nutrition Visits After Gastric Bypass Surgery for American Veterans, San Francisco, 2004-2010. Prev Chronic Dis 2014;11:140289. DOI: http:// dx.doi.org/10.5888/pcd11.140289.
\end{abstract}

\section{PEER REVIEWED}

\section{Abstract}

\section{Introduction}

Nutrition counseling is important for veterans undergoing gastric bypass surgery. The aim of this study was to explore the relationship between the number of nutrition visits a patient attended and change in body mass index (BMI) after gastric bypass surgery for the veteran population.

\section{Methods}

A retrospective study examined veterans $(\mathrm{N}=79)$ who underwent Roux-en-Y gastric bypass surgery from June 2004 through July 2010. Spearman's correlation and multivariate regression analysis were used to analyze data.

\section{Results}

A significant correlation was found between the number of postoperative nutrition visits and the change in postsurgery BMI at 2 years (Spearman's $\rho=0.21 ; P=.017$ ). After adjusting for age, sex, and race, the association between postsurgery nutrition visits and BMI change persisted ( $\beta=0.255 ; 95 \%$ confidence interval, $0.015-0.581 ; P=.039$ ).

\section{Conclusion}

Veterans with more nutrition visits following Roux-en-Y gastric bypass surgery experienced greater declines in BMI. This finding underscores the importance of the dietitian on the bariatric surgery team.

\section{Introduction}

From 2009 through 2010, the prevalence of obesity in the United States was $35.5 \%$ among adult men and $35.8 \%$ among adult women (1). Over the next 2 decades, obesity is expected to increase an additional $33 \%$ and severe obesity by $130 \%$ (2). The United States spends over $\$ 190$ billion annually on health care directly related to obesity (3). Among veterans receiving care through the Veterans Health Administration (VHA), $73 \%$ of men and $68 \%$ of women are overweight or obese (4). The incidence of obesity has increased substantially among US veterans (5). Obesity is associated with diseases in all of the organ systems, and gastric bypass surgery can prevent secondary complications of obesity.

Surgical treatment of obesity is more effective and produces longer lasting outcomes than medication therapy or counseling (6). More than 250,000 bariatric procedures were performed in the United States in 2008 (7), and that number will continue to increase. Roux-en-Y gastric bypass (RYGB) surgery has become the gold standard among bariatric surgeries, and it is the most commonly performed bariatric procedure in the United States and all over the world $(7,8)$. Gallagher et al reported that the cost of RYGB surgery at the VHA is offset by reduction of health care costs within the first year after surgery (9). The procedure is also reported to increase life expectancy by an average of 7.1 years (10). Moreover, weight loss surgery has been reported to ameliorate chronic medical conditions such as diabetes and improve quality of life $(11,12)$. In veterans, long-term follow-up has confirmed significant and durable weight loss with marked improvement in comorbidities (5). Independent studies have reported significantly 
greater weight loss after RYGB than with vertical banded gastroplasty (13). The maximum weight loss after RYGB occurs at 2 years after the surgery, and after 2 years, up to $25 \%$ of lost weight can be regained $(14,15)$. Studies have followed the RYGB outcomes up to 15 years after the surgery (16). However, few longterm follow up studies on results of RYGB have been conducted for the VHA patient population (14).

The role of the registered dietitian nutritionist is to perform dietary assessments, to evaluate for nutritional deficiencies, and to provide counseling to help patients meet postsurgery weight loss goals (17). Dietitians are part of the multidisciplinary bariatric team. Expert guidance and visits to dietitians are part of the surgical process. Veterans are an underprivileged and disenfranchised population, and they suffer from greater socioeconomic and health disparities than the general population (4). The aim of this study was to explore the relationship between the number of nutrition visits a patient made and change in body mass index (BMI) after gastric bypass surgery for the veteran population.

\section{Methods}

This project was reviewed and approved by the San Francisco Veterans Administration Medical Center Institutional Review Board and was performed in accordance with the ethical standards laid down in the 1964 Declaration of Helsinki and its later amendments or comparable ethical standards. Before analysis, patient records and information were de-identified to ensure anonymity. Data from patients who underwent RYGB at our institution from June 2004 through July 2010 were collected from the computerized patient record system. A total of 79 patients who had RYGB during the study period constituted the study population. Date of surgery, age, sex, race, height, BMI, number of nutrition encounters during the 2 years after surgery, and weight before and 2 years after surgery were recorded. Patients' weights (in $\mathrm{kg}$ ) were measured by health care professionals during clinic visits. BMI was calculated as weight (in $\mathrm{kg}$ ) divided by height (in $\mathrm{m}^{2}$ ). Change in BMI was calculated by subtracting presurgery BMI from BMI 2 years postsurgery.

SPSS version 20.0 (SPSS, Inc) was used to analyze the data. Spearman's correlation was used to determine the association between number of nutrition visits and BMI change. Multivariate linear regression was used to determine the effects of nutrition visits, sex, race, and age on BMI change. A $P$ value of $<.05$ was considered significant for this study.

\section{Results}

Characteristics of patients are shown in the Box. The mean number of nutrition encounters during the 2 years postsurgery was 6.44 visits (standard deviation [SD], 5.36; range, 1-29). The average BMI change was a decrease of 14.66 (SD, 6.26; range, 1.3-38.1) at 2 years postsurgery. There was a significant relationship between the number of postsurgery nutrition encounters and the change in BMI 2 years after surgery (Spearman's $\rho=0.21 ; P=$ .017). After adjusting for age, sex, and race, there was an association between postsurgery nutrition visits and BMI change ( $\beta=$ 0.255; 95\% CI, 0.015-0.581; $P=.039$ ) (Table).

\section{Box. Characteristics of the Study Population ( $N=79)$, Effect of Post-Surgery Nutrition Follow-up Visits on Body Mass Index Change Among Veterans, San Francisco, 2004-2010}

Age, y

Mean, 51.35; standard deviation, 8.73; range, 27-67

Sex

Male, 65 (82\%)

Female, 14 (18\%)

Race/ethnicity

White, 55 (70\%)

Black, 15 (19\%)

Hispanic, 9 (11\%)

\section{Discussion}

In this study, patients attending more nutrition visits following surgery experienced greater declines in BMI. These nutrition visitspecific results are consistent with those of Compher et al, who examined the relationship between clinical visits and post-gastric bypass weight loss and found that the odds of weight loss increased 2.8-fold with each clinical visit at 2 years following surgery (18). Lier et al found that regular attendance to postoperative nutrition counseling visits was associated with weight loss 1 year after gastric bypass surgery (19). Furthermore, Shen et al reported that patient follow-up played a significant role in the amount of weight lost after bariatric surgery (20). Patients with no follow-up visits were 4.6 times more likely to regain weight (21).

\footnotetext{
The opinions expressed by authors contributing to this journal do not necessarily reflect the opinions of the U.S. Department of Health and Human Services, the Public Health Service, the Centers for Disease Control and Prevention, or the authors' affiliated institutions.
} 
Nutrition care before surgery, during the hospital stay, and after surgery is important for the quality of life of the patient and the success of the surgery. There are no set evidence-based guidelines on the postsurgery nutrition follow-up schedule, which differs from institution to institution (22). Current VA guidelines recommend that patients have 2 to 4 nutrition visits presurgery and 2 to 3 visits during hospital stay. Furthermore, nutrition appointments should be scheduled at 1 to 2 weeks, 4 to 6 weeks, 3 months, 6 months, and 12 months after surgery, and then annually afterwards. Patients require a lifetime of nutritional follow-up to have a good quality of life (20), because bariatric surgery patients are at risk of malnutrition and micronutrient deficiencies following surgery.

Nutrition visits are helpful for bariatric surgery patients. Dietary counseling improved nutrient intake of gastric bypass surgery patients (23). Freire et al stated that lack of nutritional counseling follow-up was significantly associated with regaining weight (24). Through frequent contact dietitians can detect challenging situations such as increased food urges, inactive lifestyle, and eating fast foods, all of which can contribute to regaining weight (17). Regular nutrition visits can also aid detection and prevention of micronutrient deficiencies and severe malnutrition. Nutritional deficiencies are very common after RYGB despite supplementation with standard doses of multivitamins. The common micronutrient deficiencies that occur after surgery are potassium, B1, B3, B6, B12, folate, iron, copper, zinc, selenium, and vitamins A, D, E, K, and $C$ (22). Thus, nutrition visits can prevent regaining weight, osteomalacia, protein-calorie malnutrition, and, most of all, micronutrient deficiencies (22). Dietitians can also help prevent dumping syndrome in patients by giving appropriate dietary advice. In addition, contact with medical professionals is a source of motivation for patients (18).

This study had limitations. It was a retrospective study, and VHA patients are mostly white, male, and over the age of 50. Moreover, the sample size was small. In an older patient population, weight loss can be generally slower because of a lower metabolic rate from reduced muscle mass. Admiraal et al found that whites had more weight loss than African Americans after bariatric surgery (25). Whites made up the majority in this study population. Most published studies on bariatric surgery outcomes consist of $70 \%$ to $80 \%$ women (26). Bekheit et al found no difference in weight loss between men and women after RYGB (27). Still et al mentioned in their study that age and sex do not correlate with postoperative weight loss (28). Odom et al found no relationship between weight loss and race (21). As in the results obtained by Bekheit et al, Still et al, and Odom et al, our study found no correlation between postsurgery BMI change and age, race, or sex.
Freire et al stated that postsurgery nutritional follow-up visits can decrease dramatically as time passes (24). A significant number of patients will not comply with regular follow-up unless they are prompted to do so (29). Continued support through communication and monitoring is needed to sustain weight loss. Patient follow-up can be a challenge for veterans. Bariatric surgery is offered in only 12 medical centers in the VHA system, and some patients have to travel long distances to these centers for surgery. After discharge, they return to their primary care locations for followup. Thus, some veteran patients can be lost to follow-up, which appears to be a major barrier to postsurgery weight loss (18). Veterans, in general, are more obese or overweight, and they suffer from more illnesses than the general population (4). There is also a higher prevalence of substance abuse and mental health problems among veterans (30). Adams et al reported that veterans with a history of substance abuse had low weight loss 2 years after surgery (10). Most VHA patients are over the age of 50, have attained low education levels, and have low socioeconomic status (5). Moreover, lower socioeconomic status of veterans can limit access to exercise facilities and food choices that may have an effect on total weight loss (14).

Registered dietitians and nutritionists have an integral role in helping patients meet their weight loss goals following bariatric surgery. According to the VA guidelines, RYGB patients should have had at least 6 nutrition visits at 2 years after surgery. Strategies need to be developed to optimize the number of nutrition visits and to encourage veterans to come to all scheduled nutrition appointments. In this study, veterans attending more postsurgery nutrition visits experienced greater weight loss in the 2 years after surgery. Prospective studies may confirm the association between BMI change and the number of nutrition visits.

\section{Acknowledgments}

Support for this study was provided by the Department of Veterans Affairs under grant no. 5 IK2 CX000549-04. All authors declare that they have no conflicts of interest.

\section{Author Information}

Corresponding Author: Aung Zaw Win, MD, MA, MPH, San Francisco Veterans Affairs Medical Center 4150 Clement St, San Francisco, CA 94121. Telephone: 415-221-4810, extension 2070. E-mail: aungzwin@gmail.com.

The opinions expressed by authors contributing to this journal do not necessarily reflect the opinions of the U.S. Department of Health and Human Services, the Public Health Service, the Centers for Disease Control and Prevention, or the authors' affiliated institutions. 
Author Affiliations: Carol Ceresa, Peter Mak, Clinical Nutrition, San Francisco Veterans Affairs Medical Center, San Francisco, California; Anne L. Schafer, Department of Medicine, University of California, San Francisco, Medical Service, San Francisco Veterans Administration Medical Center, San Francisco, California; Lygia Stewart, Department of Surgery, University of California, San Francisco, Surgical Service, San Francisco Veterans Administration Medical Center, San Francisco, California.

\section{References}

1. Flegal KM, Carroll MD, Kit BK, Ogden CL. Prevalence of obesity and trends in the distribution of body mass index among US adults, 1999-2010. JAMA 2012;307(5):491-7and .

2. Finkelstein EA, Khavjou OA, Thompson H, Trogdon JG, Pan L, Sherry B, et al. Obesity and severe obesity forecasts through 2030. Am J Prev Med 2012;42(6):563-70.

3. Cawley J, Meyerhoefer C. The medical care costs of obesity: an instrumental variables approach. J Health Econ 2012; 31(1):219-30.

4. Das SR, Kinsinger LS, Yancy WS, Wang A, Ciesco E, Burdick $\mathrm{M}$, et al. Obesity prevalence among veterans at Veterans Affairs medical facilities. Am J Prev Med 2005;28(3):291-4.

5. Hauser DL, Titchner RL, Wilson MA, Eid GM. Long-term outcomes of laparoscopic Roux-en-Y gastric bypass in US veterans. Obes Surg 2010;20(3):283-9.

6. Martins C, Strommen M, Stavne OA, Nossum R, Mårvik R, Kulseng B. Bariatric surgery versus lifestyle interventions for morbid obesity - changes in body weight, risk factors and comorbidities at 1 year. Obes Surg 2011;21(7):841-9.

7. Schroeder R, Garrison JM, Johnson MS. Treatment of adult obesity with bariatric surgery. Am Fam Physician 2011; 84(7):805-14.

8. Júnior WS, Amaral JL, Nonino-Borges CB. Factors related to weight loss up to 4 years after bariatric surgery. Obes Surg 2011;21(11):1724-30.

9. Gallagher SF, Banasiak M, Gonzalvo JP, Paoli DP, Allwood J, Morris D, et al. The impact of bariatric surgery on the Veterans Administration healthcare system: a cost analysis. Obes Surg 2003;13(2):245-8.

10. Adams TD, Gress RE, Smith SC, Halverson RC, Simper SC, Rosamond WD, et al. Long-term mortality after gastric bypass surgery. N Engl J Med 2007;357(8):753-61.
11. Alami RS, Morton JM, Sanchez BR, Curet MJ, Wren SM, Safadi BY. Laparoscopic Roux-en-Y gastric bypass at a Veterans Affairs and high-volume academic facilities: a comparison of institutional outcomes. Am J Surg 2005; 190(5):821-5.

12. Christou NV, Sampalis JS, Liberman M, Look D, Auger S, McLean AP, et al. Surgery decreases long-term mortality, morbidity, and health care use in morbidly obese patients. Ann Surg 2004;240(3):416-23.

13. Brolin RE, Robertson LB, Kenler HA. Weight loss and dietary intake after vertical banded gastroplasty and Roux-en-Y gastric bypass. Ann Surg 1994;220(6):782-90.

14. Yan E, Ko E, Luong V, Wang HJ, Romanova M, Li Z. Longterm changes in weight loss and obesity-related comorbidities after Roux-en-Y gastric bypass: a primary care experience. Am J Surg 2008;195(1):94-8.

15. Heber D, Greenway FL, Kaplan LM, Livingston E, Salvador J, Still C. Endocrine and nutritional management of the postbariatric surgery patient: an Endocrine Society Clinical Practice Guideline. J Clin Endocrinol Metab 2010; 95(11):4823-43.

16. Dalcanale L, Oliveira CP, Faintuch J, Nogueira MA, Rondó P, Lima VM, et al. Long-term nutritional outcome after gastric bypass. Obes Surg 2010;20(2):181-7.

17. Kulick D, Hark L, Deen D. The bariatric surgery patient: a growing role for registered dietitians. J Am Diet Assoc 2010; 110(4):593-9.

18. Compher CW, Hanlon A, Kang Y, Elkin L, Williams NN. Attendance at clinical visits predicts weight loss after gastric bypass surgery. Obes Surg 2012;22(6):927-34.

19. Lier HØ, Biringer E, Stubhaug B, Tangen T. The impact of preoperative counseling on postoperative treatment adherence in bariatric surgery patients: a randomized control trial. Patient Educ Couns 2012;87(3):336-42.

20. Shen R, Giovanni D, Rajaram K, Cabrera I, Siegel N, Ren CJ. Impact of patient follow-up on weight loss after bariatric surgery. Obes Surg 2004;14(4):514-9.

21. Odom J, Zalesin KC, Washington TL, Miller WW, Hakmeh B, Zaremba DL, et al. Behavioral predictors of weight regain after bariatric surgery. Obes Surg 2010;20(3):349-56.

22. Fujioka K. Follow-up of nutritional and metabolic problems after bariatric surgery. Diabetes Care 2005;28(2):481-4.

23. Shah M, Adams-Huet B, Rao S, Snell P, Quittner C, Garg A. The effect of dietary counseling on nutrient intakes in gastric banding surgery patients. J Investig Med 2013;61(8):1165-72.

24. Freire RH, Borges MC, Alvarez-Leite JI, Toulson Davisson Correia MI. Food quality, physical activity, and nutritional follow-up as determinant of weight regain after Roux-en-Y gastric bypass. Nutrition 2012;28(1):53-8.

\footnotetext{
The opinions expressed by authors contributing to this journal do not necessarily reflect the opinions of the U.S. Department of Health and Human Services, the Public Health Service, the Centers for Disease Control and Prevention, or the authors' affiliated institutions.
} 
25. Admiraal WM, Celik F, Gerdes VE, Dallal RM, Hoekstra JB, Holleman F. Ethnic differences in weight loss and diabetes remission after bariatric surgery: a meta-analysis. Diabetes Care 2012;35(9):1951-8.

26. Livingston EH, Liu CY, Glantz G, Li Z. Characteristics of bariatric surgery in an integrated VA health care system: follow-up and outcomes. J Surg Res 2003;109(2):138-43.

27. Bekheit M, Katri K, Ashour MH, Sgromo B, Abou-ElNagah G, Abdel-Salam WN, et al. Gender influence on long-term weight loss after three bariatric procedures: gastric banding is less effective in males in a retrospective analysis. Surg Endosc 2014;28(8):2406-11.

28. Still CD, Benotti P, Wood GC, Gerhard GS, Petrick A, Reed $\mathrm{M}$, et al. Outcomes of preoperative weight loss in high-risk patients undergoing gastric bypass surgery. Arch Surg 2007; 142(10):994-8.

29. Harper J, Madan AK, Ternovits CA, Tichansky DS. What happens to patients who do not follow-up after bariatric surgery? Am Surg 2007;73(2):181-4.

30. Adams CE, Gabriele JM, Baillie LE, Dubbert PM. Tobacco use and substance use disorders as predictors of postoperative weight loss 2 years after bariatric surgery. J Behav Health Serv Res 2012;39(4):462-71. 


\section{Table}

Table. Multivariate Linear Regression Analysis of Factors Affecting PostSurgery Weight Loss Among Veterans $(\mathrm{N}=79)$ for the Effect of Nutrition Visits on Postsurgery Body Mass Index Change, San Francisco, 2004-2010

\begin{tabular}{|l|r|r|r|}
\hline Variable & \multicolumn{1}{|c|}{$\boldsymbol{\beta}$} & $\boldsymbol{P}$ value & 95\% Confidence Interval \\
\hline Postsurgery nutrition visits & 0.255 & .04 & 0.015 to 0.581 \\
\hline Age & -0.091 & .45 & -0.238 to 0.107 \\
\hline Sex & -0.004 & .96 & -3.181 to 3.342 \\
\hline Race & 0.006 & .97 & -1.74 to 1.683 \\
\hline
\end{tabular}

